\title{
INTERACCION GAMETO-EPITELIO EPIDIDIMARIO DURANTE LA MADURACION POST-TESTICULAR DEL ESPERMATOZOIDE DE MACHO CABRIO
}

BUGO GONZALES - FIGUEROA (*)

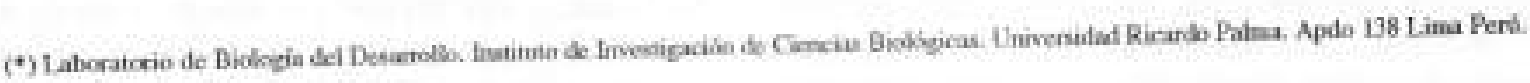

\section{RLSEMEN}

En el presente trabajo se relaciona la isteracción estercocilass de Jas cólhlas principales del epiteló - espermatozoide, coe el grado de funcionalidad integral de la memlerana plasmatica (RHE) y la evaluación de madurez de la cromatina nuclear (CROMAT) durante la maduración postesticular el espernatazoide de macho calorío.

Los estereocilios de las células principales, en el caput cpicicimario, orientan su extremb disal hacia el jumen donde se encoentran los espermatozoides. En este segmento epididimario el aumesto del grado de madurez de la membrana plasmática $295 \%$ ) y la coodensación de la cromatia nuclear $\{26.75$ s son relativamente bajos. Fa el limite entre cagut y corpus los extremos de los estereocilios, de forma glabulat. contactan con. ha superficic espermática. proceso que coincide con el madurez de la memtirana plasmatica ( $48.9 \%$ ) y de 1 la condensición de la cromatisa nuelear $(30.0 \%)$.

La inmadurez morfológlea del espermatozoide experada por la presencia de la gota cjtoplamática y de vesiculas en su extremo posterior del I nagelo en capat y corpus, los valores eneontrados pura is RHE (80.75) y CROMAT (95, 69\%), en la cavda la ansencia de vesiculas globulares en las cstereocijos de este segmento, apoyarian ha idea de que la icular del expermatozoide es consecuencia del intercambic de secreciones del epididimo, las que se dan por la interaceión entev la superficie de las eslatas epiteliales priscipales y de la célula espermática.

\section{SUMMARY}

The relationship between sperm epitelial selis stereosilia interaction with asses the functional integrity of the sperm caprine membrane (RHE) and evaluation of nuclear condessatioo cramatin (CROMAT) have been studied during postesticular sperm maturation.

Principal cells stereocilia of caput epididymis have form of vesicles in tap distal, in the lumen there are many spermatozoa which show Jow percenaze of sperim membrane maturity $\{29.6 \%)$ and suelear cromatin cobdensation $(26.75)$.

Between caput and corpus stereocilia top distal conolact with sperm inembrane surface. In this zone there are $48.9 \%$ of sperm membrane maturity and $30.0 \%$ with cromatin condensed.

The sporm morphelogical inmaturaty expressed for cytoplasmatic diroplet and vabuas soon as the absence of vesicles corpes and porcentages $(80.7 \%)$ for RIIE and CROMAT $(95.69 \%)$ in the efididymaticular is consecuence of interchanges of in the stereocilia of cauda principal cells, kuggeste tha speminge surface

\section{INTRODUCCION}

El espermatozovide de mamifero al dejar ta matric testicular, necesita interciambiar sestanciascon lascélulas epiteliales para adquirir las condiciones que lo conduz. can a ser capaz de fertilizar los ovocitos.

F) epididimo es un órgatno crucial, puesto que cuando el espermatozoide atraviesa este conducto logra una serie de condiciones que modulan su condición fértil. Durante el tránsito cpididimario, el gameto obtiene motilidad progresiva. moditica su morfologia condensa la cromatina nuclear y experimenta notahles variaciones en el contenido de las proteísas de lat membrana plasmática (Burgos, 1989). El proceso de maduración espermática (Orgebin - Crist, 1969), requiere de inieracciones secucnciales con el fluido de las diferentes regiones del epididimo.

El epitelio epididimario de los mamiferos, está compuesto, generalmente, de células principales, basales de linfocitos, macrófagos y monocitos dispersos entre las celulas mencionadas (Robaire \& Hermo, 1988). I as células principales tienen como funcion priacipal crear y mantener las caracteristicas regionales del fluido epididimal (Aman, 1987) Estas diferencias se expresan por la manera como disponen las celulas epiteliales en los diferentes 
segmentos del epididimo. En carncro, la cantidad de celulas principales que se encuentran en el "caput" es mayor con respecto a las que se visualizan en la cauda, micntras que la proporción de las células basales es similar en todos los segmentos del epididimo (Marengo \& Amann, 1990).

El desplazamiento de la gota citoplasunática que se observa a partir del corpus y la formación de asociaciones de losespermatozoides tipo roseta (mata) o "roeulaux" (cobayo)que se incrementan hacia la cauda serian indicadores importantes de la maduración espermática (Burgos, 1992).

Es evidente, que la interacción epidfdimo - gameto cumple un papel importante en la maduración posttesticutar del espermatozoide. En el presente trabajo se relaciona la interacción: estereociltos de las células principales y el espermatozoide, con el análisis de la integridad funcional de la membrana plaunática del espermatozoide y la condensación de la cromatina noclear.

\section{MATERIALES Y METODOS}

\section{Obtención de los epidídimes.}

Los epididimos de macho cabrio se obtuvieron de tas colectas hechas en el centro de beneficiode Yerbateros (Ate - Lima). Los ejemplares colectados fucron transportados at laboratorio en la bolsa escrotal en un periodo de 1 a 2 hrs. después de sacrificado el animal. Fueron examinados 10 epidtidimos de macho cabrio con un peso promedio de 12.3 gramos; se asumió que los epididimos con un peso inferior a 10.5 gnumos pertenecieron a animales que eyacularon antes de ser sacrificados, por lo que se descartaron.

\section{Preparación del epididimo para la microscopía de barrido.}

Se disectaron caput, corpus y cauda del epidfdimo y cada uno de los segmentos fueron fijados por separado en glutaraldehido $4 \%$ tamponado en buffer fosfato y posfijados en tetróxido de osmio. Posteriomente las muestras fueron deshidratadas en una serie creciente de alcoholes y procesados convencionalmente para microscopia electrónica de barrido, mediante secado a punto critico y sombreado con oro; de esta manera se observaron al microsecopio electrónico de barrido marca Jeol.

Evaluación de la integridad funciomal de la membrana plasmática y evaluación de la madurez nuclear.

Se trozaron pedazos de caput, corpus y cuuda y se prepararon de acuerdo a la técnica de Jeyendra et al., (1984). Para analizar la respuesta hiposmótica de la membrasa plasmática, se verifica el binchamiento de la cola del espermatozoide a través de un microscopio optico a $400 \mathrm{x}$ đe magnificación. Se cuentan 400 células en 4 campos diferentes, considerindose un resultado normal cuando se visualiza el hinchamiento en el $60 \%$ de las cellulas espermáticas.

Para evaluar la condensación de la cromatina nuclear se utilizó el método de Terquen \& Daudone (1983). Se contaron 400 núcleos por lámina a través de un microscopio 6 ptico a $1000 \mathrm{x}$ de magnificación diferenciándose núcleos condensados, parcialmente condensados y descondensados.

\section{RESULTADOS}

Análisis de la ultraestructura de las diferentes regiones del epidádimo.

Las interacciones gameto - epitelio, pueden estudiarse en los diferentes segmentos del cpidídimo.

En el boode apical de las células principales del caput epididimario se observan esterencilios de diferentes longitudes (Fig. 1) cuyos extremos distales se proyectan hacia el lumen (Fig. 2), asi como la presencia de numerosos espermatozoides en la luz del túbulo.

Los estereocilios presentan en su extremo distal forma de vexicula y se asocian estrechamente a los espermatozoides en el límite de caput y corpus epididimario (Fig. 3 y 4 ).

Cuando los espermatozoides se encuentran en la cauda epididimaria la interacción de los espermatozoides con los estereocilios es evidente (Fig. 5) y el contacto es a través del extremo distal de estos, careciendo ta mayoria de ellos de las vesículas observadas en caput y corpus del epididimo. Asi mismo (Fig. 6), gran parte de los espermatozoides estín unidos cabeza-cabeza a través de estructuras tipo fibrillas que emergen de la superficie de cada uno de ellos, semejando un "roeulaux".

Ea el lumen del corpus epididimario se puede observar espermatozojdes inmaduros que presentan gota ciloplasmática (Fig. 7), en caubio, la ausencia de la gota citoplasmática en la cauda se expresa el estado de madurez morfologica ( $\mathrm{Fig} .8$ ).

Análisis de la integridad funcional de la membrana plasmática y la condensación de la cromatina muclear del espermatozoide.

Et análisis de la integridad funcional de la membrana plasmática indica el grado de madurez del espermatozoide en los diferentes segmentos del 


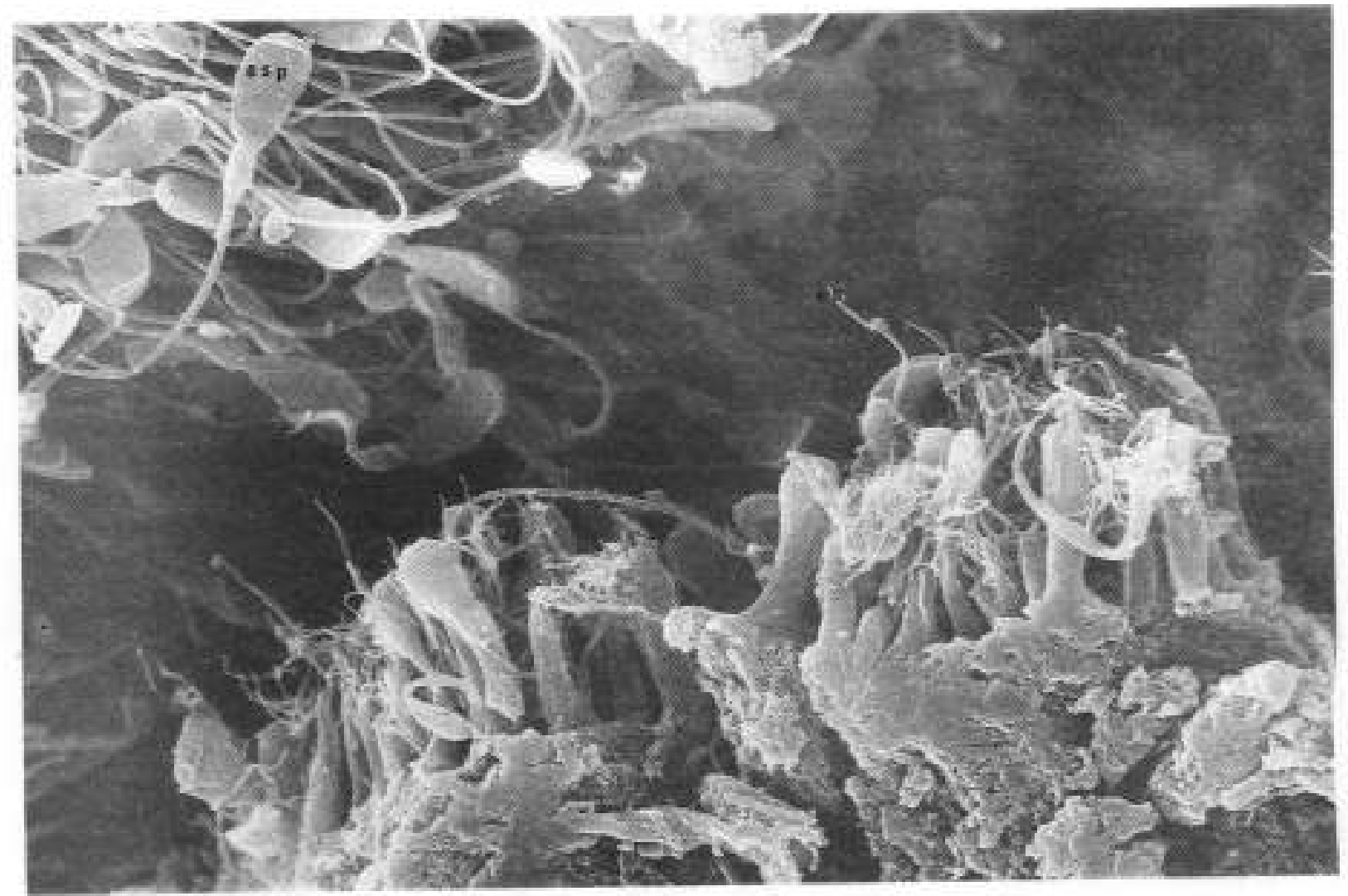

Figuru 1. Caput del epididimo de macho cabrio. Se observa los estereocilios (ee) de diferventes longirndes que

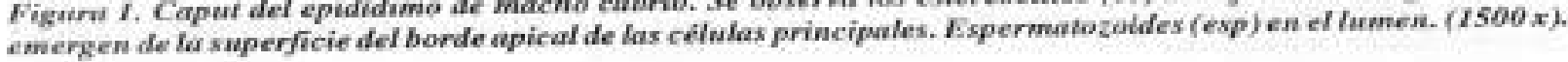

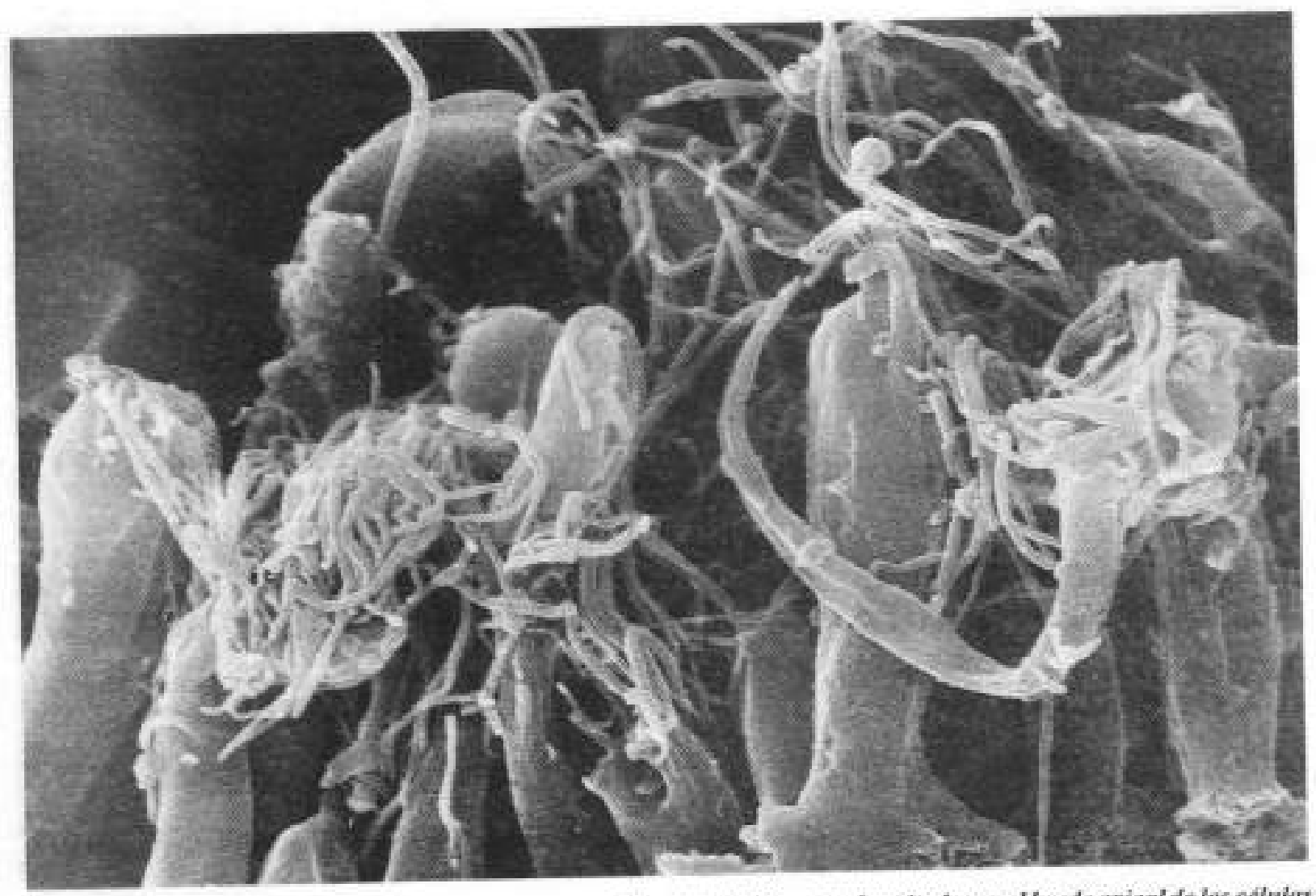

Figura 2 Capus del epididimario. Se obsernan exieneocilies (ec) de diferentes longitudes en el borde apical de las celhelas principales $(4500 x)$. 


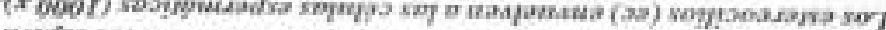

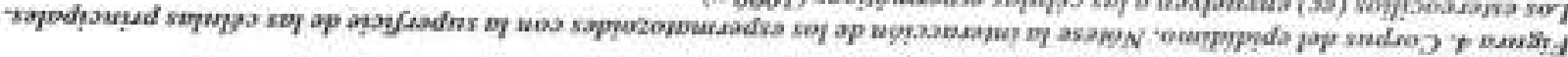

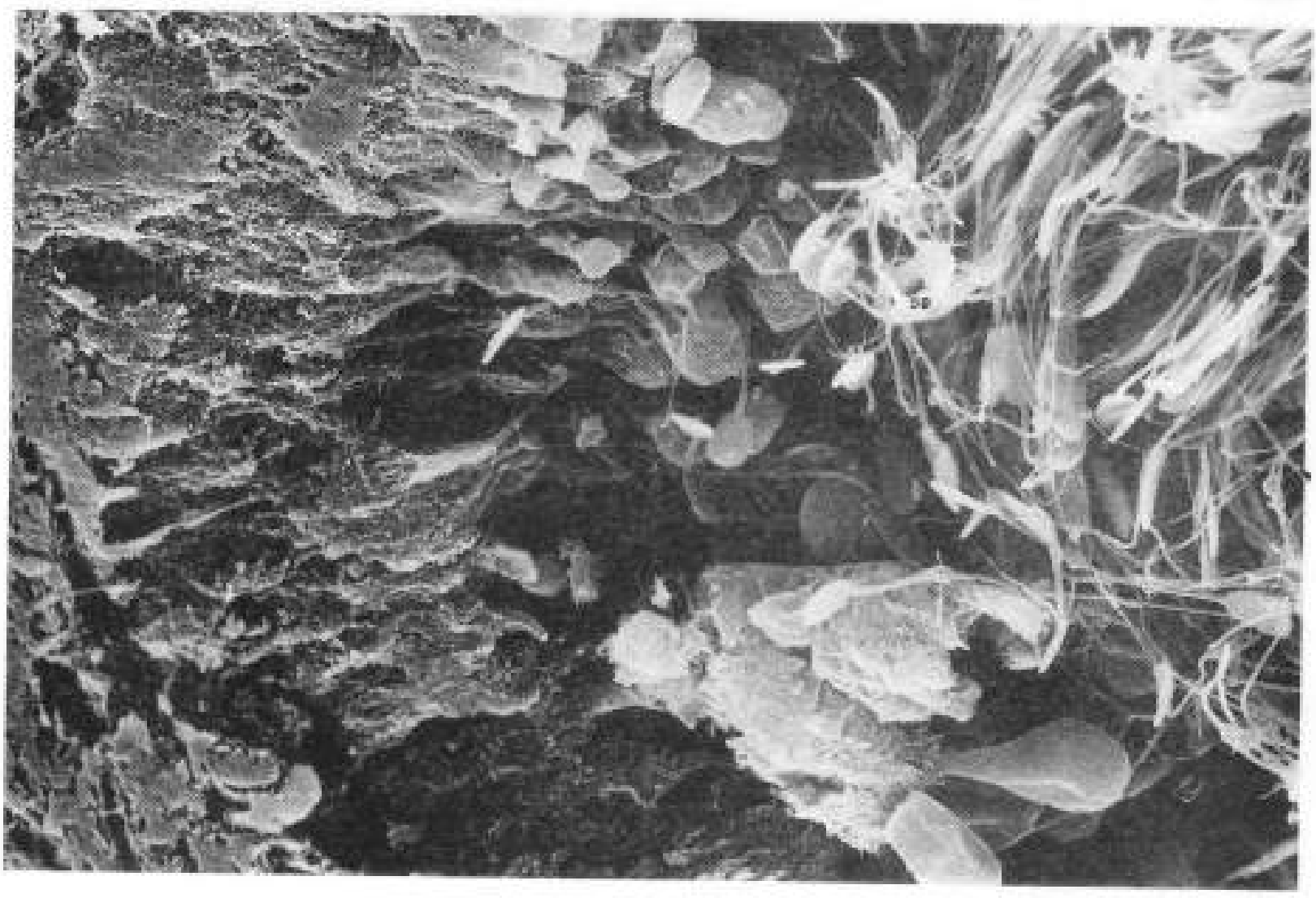

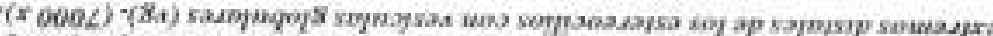

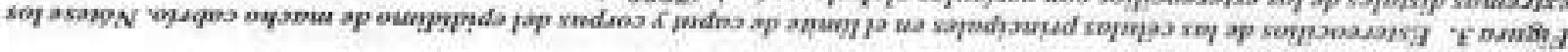

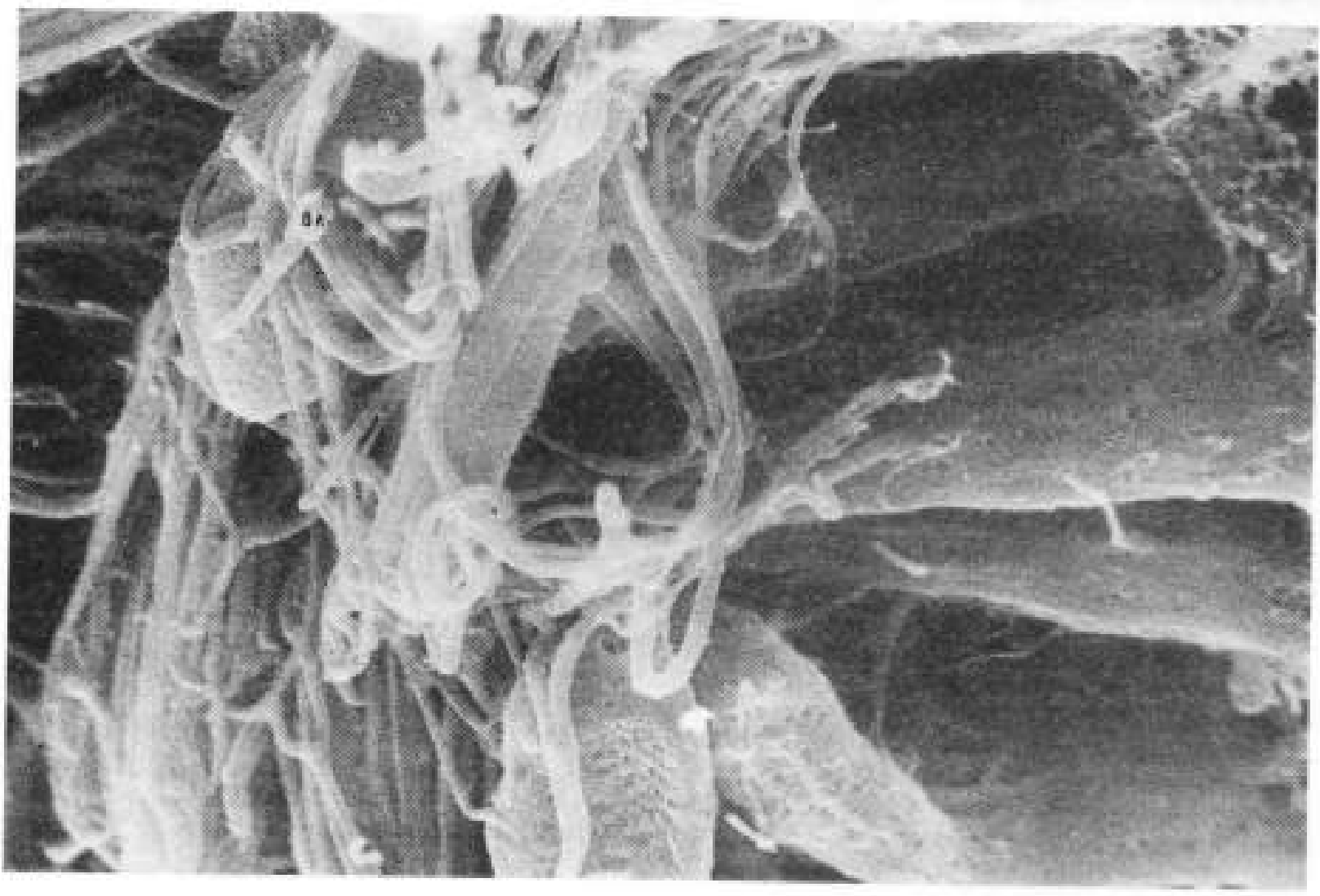




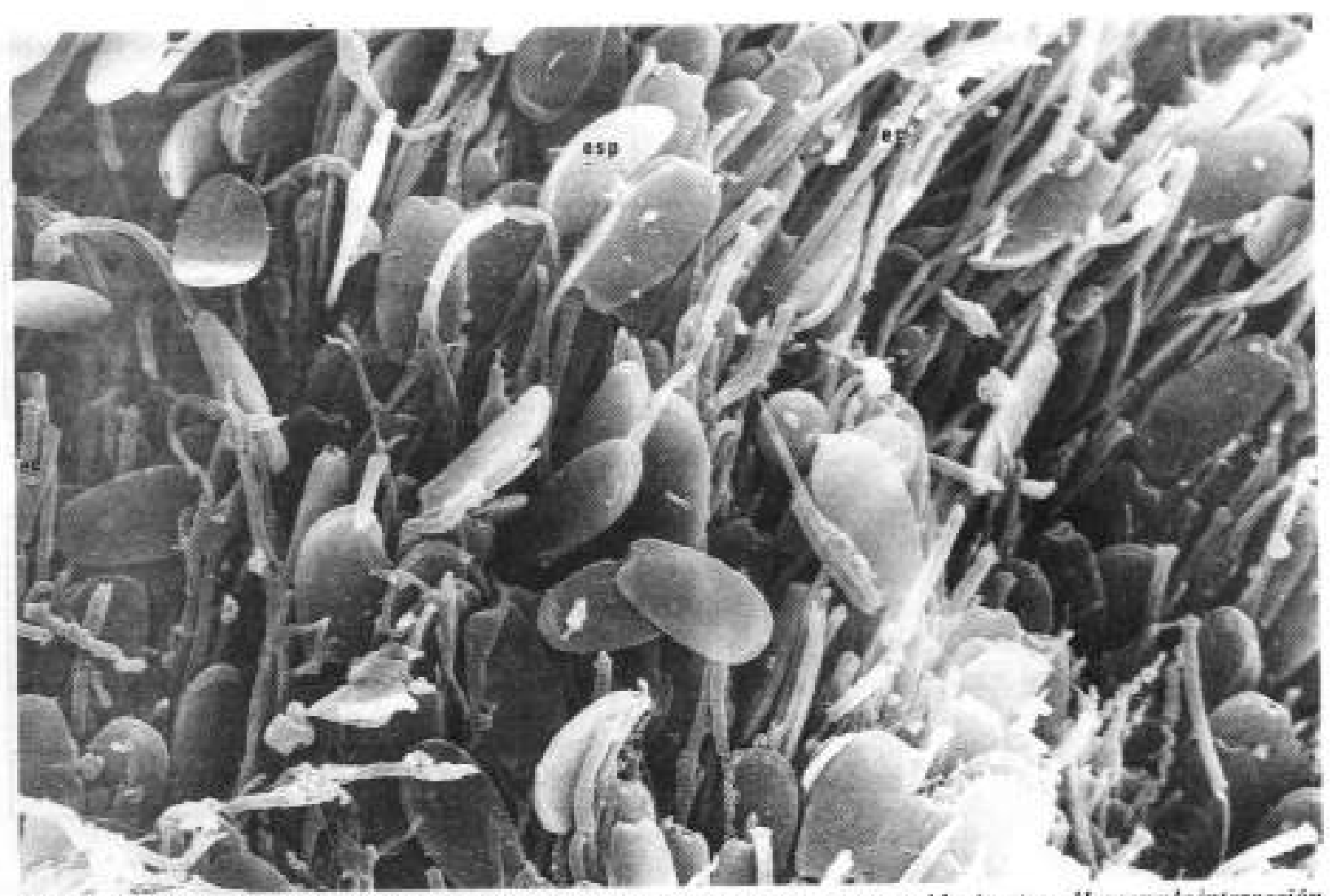

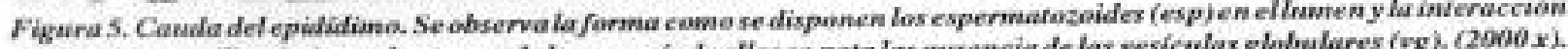
can las estervocilias (ec), en el extreme de la mayoría de ellos se nota las ausencia de las vesículas globulares (vg). (2000x)

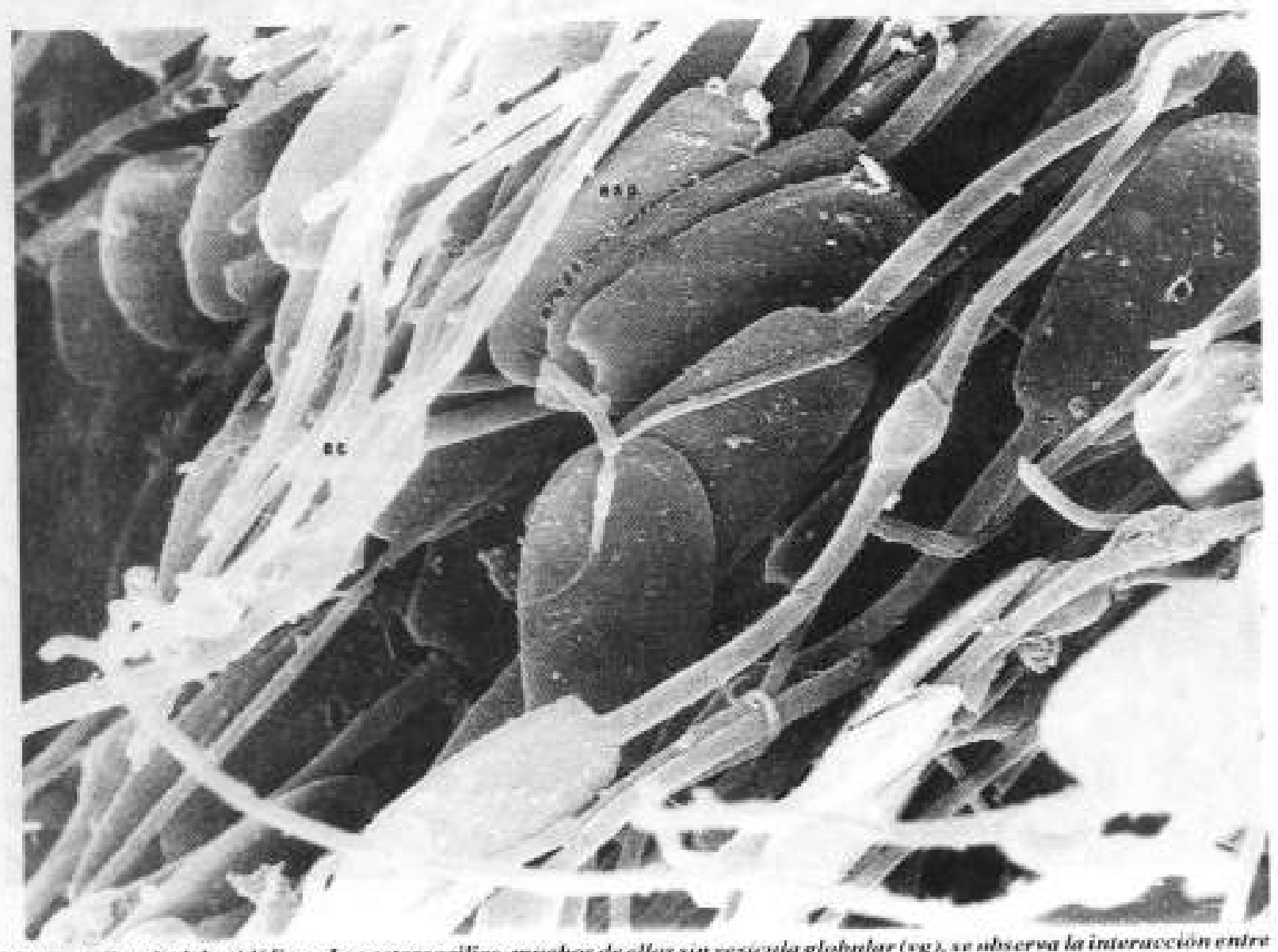

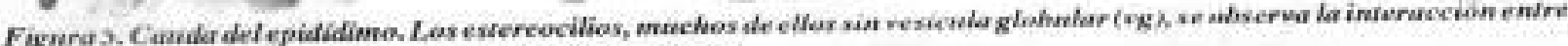
la supenficit do las cabezas de espermatoztaides. (4500x). 
epididimo del macho cabrio.

Las valores de la reacción hiposmótica de la membrana plasenática del espermatozoide (RHE +) se incrementan desde el caput a la caudaepididimaria (tabla No, 1 y gráfico No. 1). Los porcentajes en caput (29.6\%), corpus (48.9) y cauda $(80.7 \%)$, indican la progresión de madurez durante el tránsito epididimario.

El grado de condensación de cromatina es un buen indicador para evaluar la madurez noclear de la población espermática en los diferentes segmentos del epididimo.

El porcentaje de espermatozoides condensados y semicondensados en caput $(26.7 \%)$, corpas $(30.2 \%)$ y cauda $(95.69 \%)$ indican que li condensación de la cromatina nuclear ocurre en forma similar a la madurez de la membrana plasmática durante el trínsito epididimario, (tabla No, 2 y grafico No, 2).
TABLA. I PROMEDIO DE RUE EN EPHDIOHO OE WACHO CABNIO

\begin{tabular}{|l|c|c|}
\hline $\begin{array}{l}\text { Region del } \\
\text { epididimo }\end{array}$ & R. H.E + & R.H.E.- \\
\hline CAPUT & 29.655 & 70.341 \\
\hline CUFRPO & 48.935 & 51.073 \\
\hline CAUDA & 80.742 & 19.257 \\
\hline
\end{tabular}

TABLA2 CONDENSACTON DE LA CROMATINA NECLFAR EN LAS REGIOVES DEL EPIDIDUMO DE MACHO CARRIO.

\begin{tabular}{|l|c|c|c|}
\hline \multirow{2}{*}{ Regiones } & \multicolumn{3}{|c|}{ Nócleos } \\
\cline { 2 - 4 } & condensalos & $\begin{array}{c}\text { parcialmente } \\
\text { condensados }\end{array}$ & $\begin{array}{c}\text { descen } \\
\text { densados }\end{array}$ \\
\hline CAPUT & 5.7 & 21.05 & 73.25 \\
\hline CUERTO & 10.7 & 19.5 & 69.8 \\
\hline CAUDA & 79.62 & 16.07 & 4.31 \\
\hline
\end{tabular}

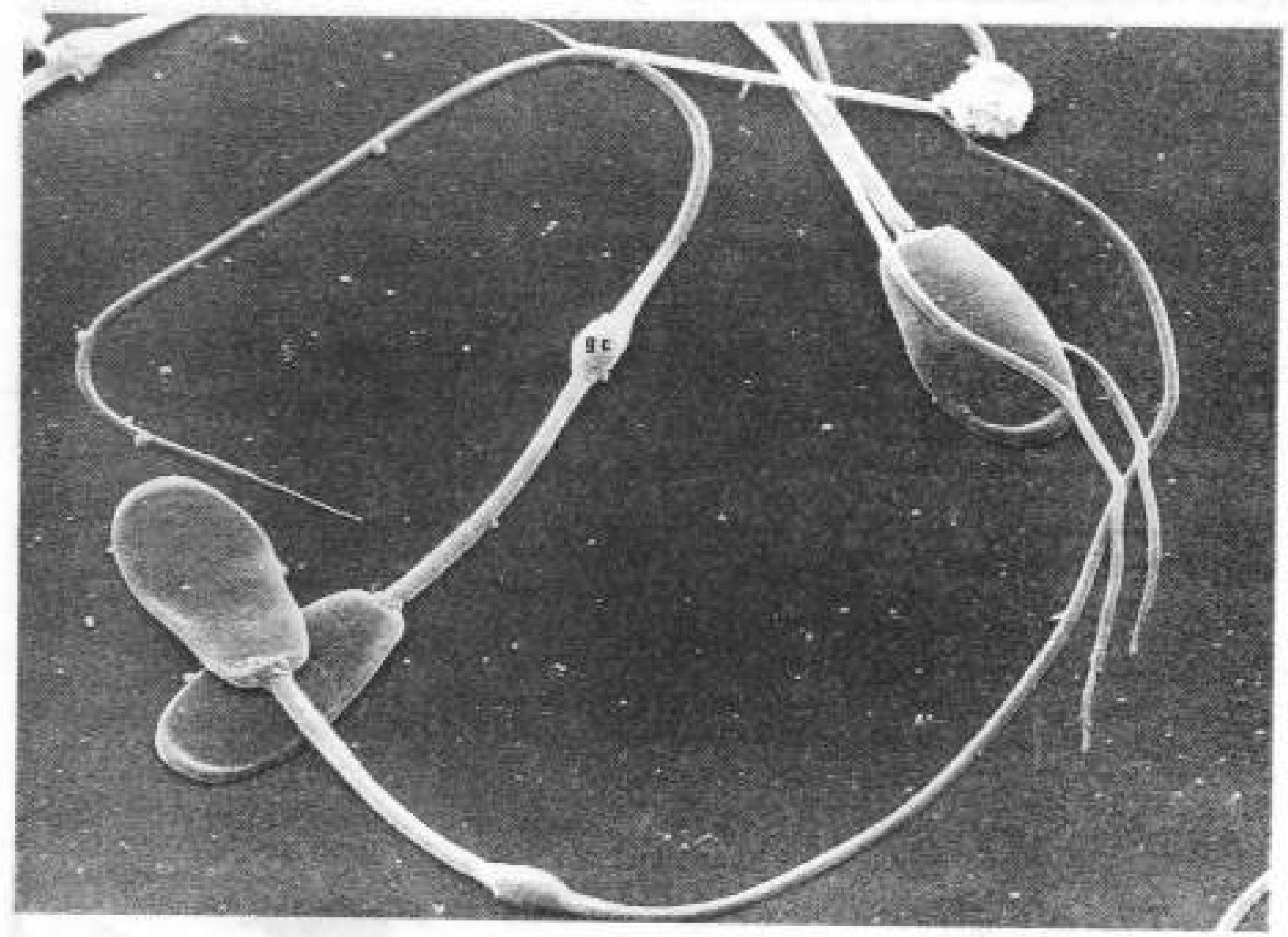

Figura 7. Espermatazoxides inmaduros del corpus del epididimo de macha cabrio. Se observa la gota cifoplasmaitica (ge) y protuberancias en la mitred pasterior del flagelo. $(3000 x)$. 


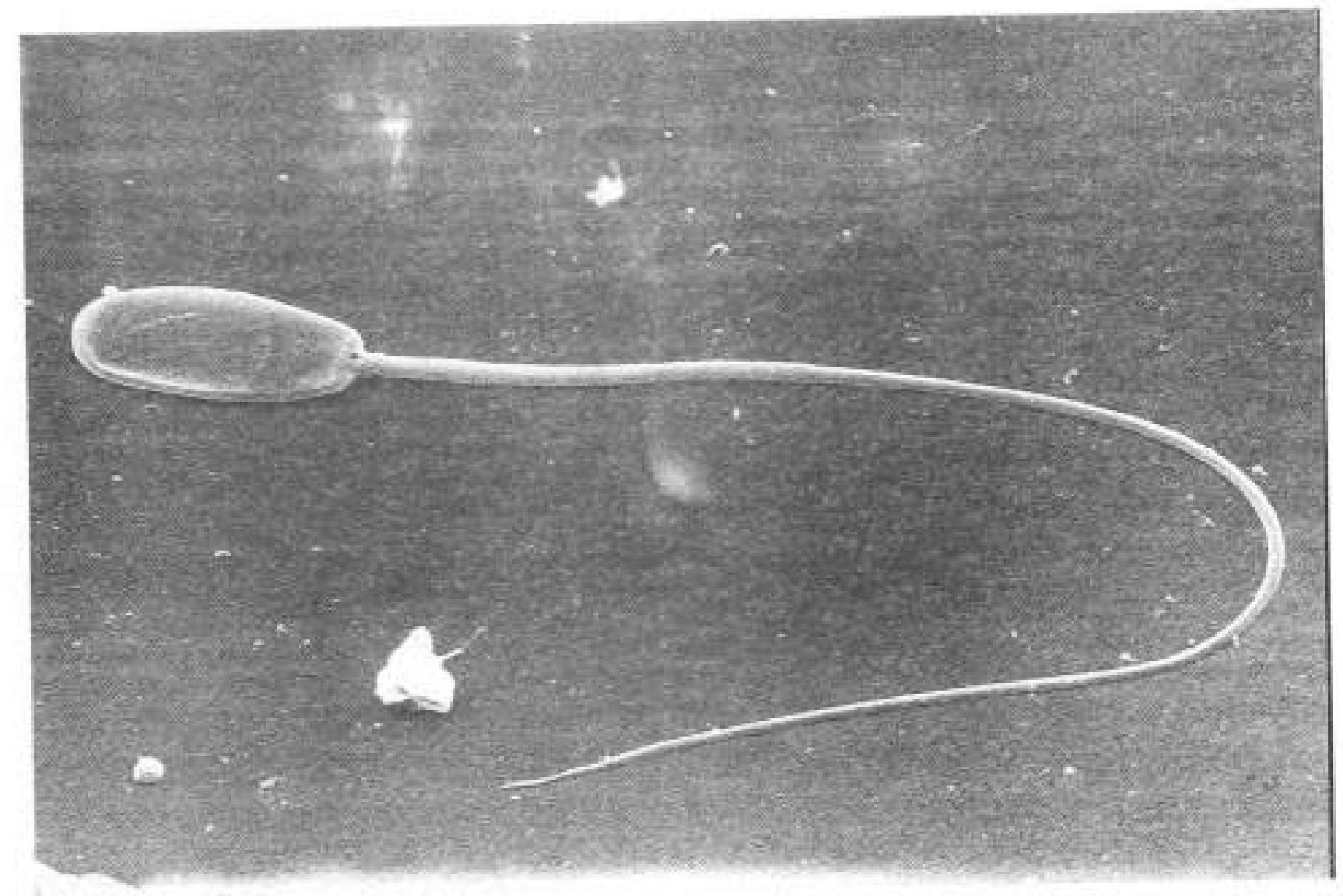

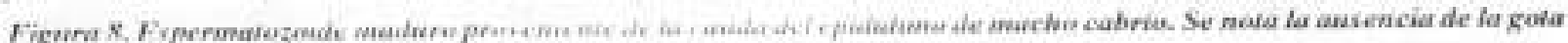

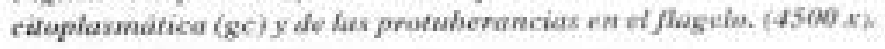

Grafico 1. Reacción híposmótica (R.H.E.) de la membrana plasmática

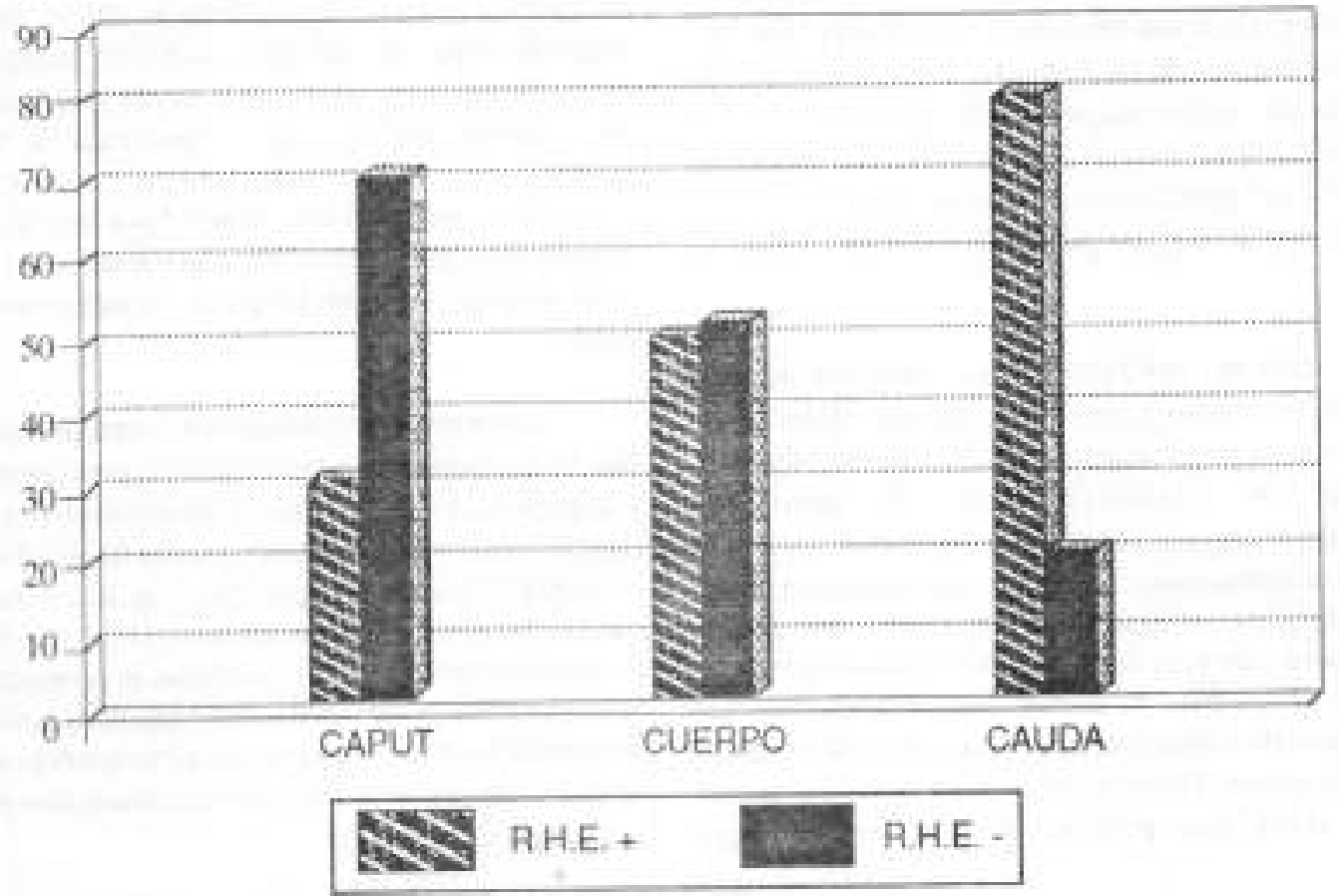




\section{Gráfico 2. Condensación de la cromatina nuclear en epididimo}

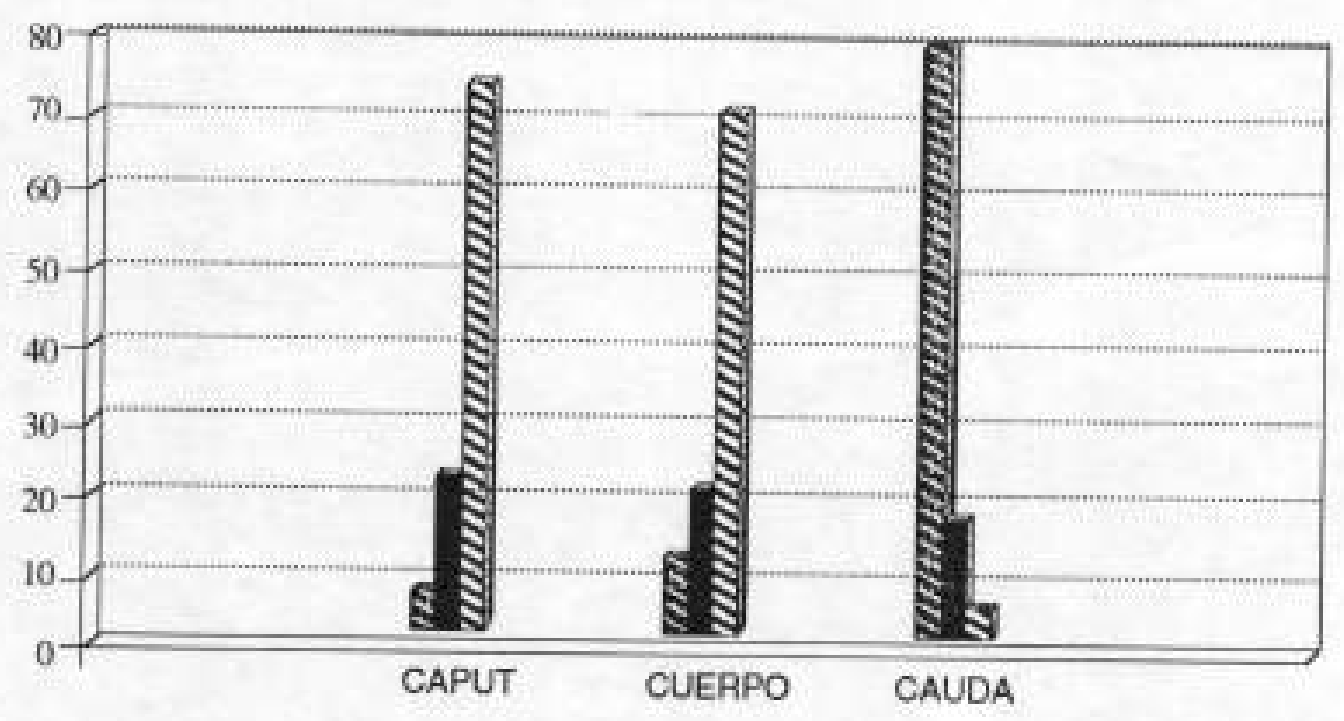

\section{DISCUSION}

E epididimo de mamífero es una verdadera camara de maduración del espermatozoide a través de la secreción de proteinas andrógenos dependiente, este proceso se debe a una interacción gameto - epididimaria gobemada por este tipo de proteinas (Burgoseral., 1993).

Los estereocilios a las células principales, en el caput epididimario de macho cabrio, oricntan su extremo distal de forma globular hacia el lumen doade se encuentran los espermatozoides, disposición que puede relacionarse con la madurez de la membrana plasmática y la condensación de la cromatina nuclear que en este segmento son relativanente bajos (tabla No. 1). Los valores encontrados tanto para la RHE y la procba de CROMAT son parecidos a los reportados Por Bustos Obregón (comunicación personal) en el epididimo de potro.

El caput del epididimo de rata contienè muchos tioles que se oxidan a disulfuros durinte el pasaje de corpus a cauda, proceso que estí intimamente relacionado con la adquisición de la motilidad espermática.(Seligmanet al., 1992), Los espermatozoides de macho cabrio empiezan a tener una motilidad sostenida (Gonzáles - Figueroa et al., 1993) en corpos epididimario y es precisamente en el límite entre capat y corpas (Fig. No, 3) donde los extremos de los estereocilios de forma globular, contactan con la superficie espermática. Esta interacción que aparece en esta region, seria una prueba de que los cambios morfofisjológicos en la célula espermática đurante su paso por el epididimo, se deben a factores extrinsecos.

Existen proteinas de membrana como la SP -10 , localizada deatro del acrosoma, (Herr et, al., 1990); la PH - 30 ubicada en la parte posterior de ta cabeza, tiene un papel fuedamental en la fusión de los gametos (Primakoff et al., 1987). las que están enmascaradas hasta la region del corpus del epididimo y cuando los espermatozoides contactan el epitelio con sus esterexcilios se hacen visibles (Burgos op. cit.). La interacción gameto - epididimario que se encuentra a partir de compus a cauda (Figs, 4,5 y 6), indicarfa que en el epididimo de macho cahrio ta madurez espermática está regulada por ese tipo de proceso. Es interesante resaltar como los estercocilios en cauda carecen de vesiculas en sus extremos distales por que seguramente su contenido pudo integrarse a la membrana plasmática en el cornus o a lo mejor en el segmento inicial de la cauda.

Lainmadurezmorfológica del espermatozoide (Fig. No. 7) expresala por la presencia de la gota citoplasmática y la presencia de vesiculas en su extremo posterior del flagelo, asi como los valores para la RHE y CROMAT, en caput y corpus comparados con lo encontrado en caudia en el aspecto morfológico (Fing. No. 8) y en to fisiologico (tablas 1 y 2), apoyarian la propoesta de que la maduración postesticular del espermatozoide es consecuencia del intercambio de secreciones del epidfimo, las quese dan por la intemacciónentre lascélulas epiteliales y la célula espermática. 
Agradecimiento: Quiero expresar mi gratitud al Dr. Claudio Barros Rodrigucz y a la Blga. Martha Valdivia Cuya del Laboralorio de Émbriologia de In Facultal de Ciencias Biológicas de la Pootificia Universidad Católica de Chile, por la gentileza de procesar las

\section{REFERENCIAS BIBLIOGRAFICAS}

AMAN, K.P. 1987 Function of the epididdymis in bulls asd ram. Joumal of Reproduction aed Fertility (suppl) 34: 115 .131

BURGOS, Mf.H. 1989. Epididymal maturation of spermatoxoz. Archivos de Biologia y Medicina Experimental $22: 190$ abst.

BURGOS, M.H FORNES, M. W. , GUTIERREZ, LS. \& VICENTI, A. 1993. El ptoceso de maduración del espernatozoide durante el tránsito epididimario. En: Prozresos en Biologia Celular (Becerra J.. Peréz. Figares JM. Fernaindez - L.lebrez. P. eds), pp 99-103

GONZALES FIGUEROA, H. 1988. Analisis do la capacidad fértil del espermatozoide de cuy en función a la estabilidad territorial de la cauda del epididimo. Tesis Doctoral UNMSM. $141 \mathrm{pP}$.

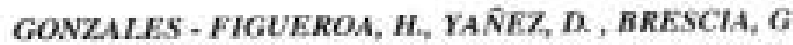
„PACHECO, F.\& STUCHI, M. 1993. Manejo reproductivo integral en saprinos: supervivencia del espermatozoideepollidimario en condiciones hipotérmicas. Tradición 1: 83-86

HERR, J.C., FLICKINGER, CH.J., HOMYK, M., KLOTZ, K., \& JOHN, E. 1990. Biocbemical and morphological characterization of the intra-acrosomal antigen SP - 10 from human sperm. Biology of Keprodaction. 42: 181 193.

JEYENDRA, R.S, VANDEER VEN, H.H.,PERFZ PELAEZ, muestras para el microscopio electrónico de barrido. Asi mismo expreso mi reconocimiento al Consejo Nacional Je Ciencia y Tecnologia (CONCYTEC) por la subvención económica otorgada para rcalizar el presente trabajo.

M., 1984. Development of an assay to asses the functionat integrity of the human sperm memhrane and the relationship to other semen characteristics, Journal of Reproduction and Fertility, $70,219: 228$.

MARENGO, S. K., \& A MAN, R. P. 1990. Morpological feature of principal colls in the ovise epididymis: $A$ quantitative and qualitative study. Biology of Reproduction. 42: 167 179.

ORGERIN-CRIST, M.C. 1969, Studies on the function of opididymis. Biology of Reproduction 1: 155 - 175

PRIMAKOFF, P., HYATT, H. \& TKEDICX - KLINE, J. 1987. Ldentification and purification of asperm surface protein with a potential role in sperm - egg membrane fusion. Jow of Cell Biology 104: 141 - 149.

ROBAIRE, B., HERMO, L., 1988, Erferent ducts, epididymis und vas deferens: structure, functions, and their regulation, Is t The Pbysiology of Reproduction. Vol 1. Knobid E, Nell JD, eds. Raven Press pp. 999- 1089.

SELIGMAN, J., KOSOWER, N.S., \& SHALGI, K. 1992 Effects of caput ligation on rat sperm and epididymis : protein thiols and fertilizing ability. Biology of Reptoduction. 46: 301-308.

TERQUEN, A., \& DADOUNE, P. 1983, Analiwo blue staining of human spermatozoa chromatin : Evaluation of auclear maturation. In : The sperm cell. André J, ed. The Hague, Martinus, Nyboff Publishers. 249 - 252. 